Abstract P289 Table 1 Results of 135 patients undergoing EBUS-TBNA as a first line investigation for mediastinal and/or hilar lymphadenopathy

\begin{tabular}{|c|c|c|c|c|c|c|c|}
\hline Group & $\begin{array}{l}\text { Patients } \\
\text { (n) }\end{array}$ & $\begin{array}{l}\text { Patients with } \\
\text { diagnostic test }\end{array}$ & $\begin{array}{l}\text { Nodes } \\
\text { sampled }\end{array}$ & $\begin{array}{l}\text { Number of } \\
\text { total passes }\end{array}$ & $\begin{array}{l}\text { Inadequate } \\
\text { samples (n) }\end{array}$ & $\begin{array}{l}\text { Diagnostic } \\
\text { samples (n) }\end{array}$ & Diagnosis of samples \\
\hline 1: IMHL- & 35 & $34(97 \%)$ & 66 & 151 & $5(8 \%)$ & $61(92 \%)$ & $\begin{array}{l}\text { Reactive: } 45(74 \%) \\
\text { Malignant: } 4(6 \%) \\
\text { Non-caseating } \\
\text { granulomas: } 12(20 \%)\end{array}$ \\
\hline 1a: IMHL with no radiological suggested diagnosis & 13 & $13(100 \%)$ & 24 & 44 & $1(4 \%)$ & $23(96 \%)$ & $\begin{array}{l}\text { Reactive: } 17 \\
\text { Malignant:2 } \\
\text { Non-caseating } \\
\text { granulomas: } 4\end{array}$ \\
\hline 1b: IMHL with radiologically suggested diagnosis & 22 & $21(95 \%)$ & 42 & 107 & $4(10 \%)$ & $38(90 \%)$ & $\begin{array}{l}\text { Reactive: } 28 \\
\text { Malignant: } 2 \\
\text { Non-caseating } \\
\text { granulomas: } 8\end{array}$ \\
\hline $\begin{array}{l}\text { 2: radiologically diagnosed likely lung cancer with } \\
\text { mediastinal lymphadenopathy }\end{array}$ & 90 & $86(96 \%)$ & 145 & 279 & $8(6 \%)$ & $137(94 \%)$ & $\begin{array}{l}\text { Reactive: } 60 \\
\text { Malignant: } 76 \\
\text { Non-caseating } \\
\text { granulomas: } 1\end{array}$ \\
\hline $\begin{array}{l}\text { 3: other e.g. known/suspected malignancy } \\
\text { (excluding lung), previous cancer diagnosis, } \\
\text { post cancer treatment }\end{array}$ & 10 & $10(100 \%)$ & 19 & 40 & 0 & $\begin{array}{l}19 \\
(100 \%)\end{array}$ & $\begin{array}{l}\text { Reactive: } 13 \\
\text { Malignant: } 4 \\
\text { Non-caseating } \\
\text { granulomas: } 2\end{array}$ \\
\hline
\end{tabular}

\section{P290 DO LUNG FUNCTION INDICES CORRELATE WITH RISK OF PNEUMOTHORAX FOLLOWING CT-GUIDED BIOPSY?}

P Griffiths, J Heaton, S Claxton, D Hughes. Wirral University Teaching Hospital NHS Foundation Trust, Liverpool, UK

\subsection{6/thoraxjnl-2015-207770.426}

Introduction CT-guided lung biopsy is a widely used and established technique for the diagnosis of lung lesions, and several risks are well described. The most common complication is pneumothorax, occurring in approximately $20 \%$ of cases. We aimed to characterise the risk of post-procedure pneumothorax in our patient population, and determine whether lung function indices correlate with the incidence of pneumothorax.

Methods Patients undergoing CT-guided biopsy of intraparenchymal lesions from January 2014-2015 were retrospectively identified. Patients were stratified in to those with and without post-procedure pneumothorax. Spirometry and transfer factor for carbon monoxide (TLCO) were reviewed and compared using an unpaired $t$ test.

Results 111 procedures were performed in 111 patients (53 men 58 women; mean age 70.4 years; range 40 to 88 ), all done for suspected malignancy. Pneumothorax was identified in 25 patients post biopsy (21\%; age range 61 to 87 ; mean \pm SD age, $73.4 \pm$ 6.7), 12 female (48\%) and 9 patients (36\%) had emphysema.

Of the 25 patients with pneumothorax, $\mathrm{FEV}_{1}$ ranged from 32 to $115 \%$ predicted $(80.5 \% \pm 23.57 \%)$ and FVC ranged from 54 to $125 \%(91.9 \% \pm 19.1 \%)$. TLCO was available for 14 patients, range 34 to $99 \%$ predicted $(71.5 \% \pm 19.2 \%)$. Of the 86 patients with no pneumothorax, FEV1 ranged from 27 to $126 \%$ predicted $(73.9 \% \pm 29.9 \%)$ and $\mathrm{FVC}$ ranged from 38 to $139 \%$ predicted $(85 \% \pm 21.9 \%)$. TLCO was available for 50 patients $(58 \%)$, range 31 to $108 \%$ predicted $(63.2 \% \pm 18.9 \%)$.

There was no significant difference in $\mathrm{FEV}_{1}(\mathrm{p}=0.199)$, FVC $(\mathrm{p}=0.109), \mathrm{FEV}_{1} / \mathrm{FVC}$ ratio $(0.99)$ or TLCO (0.176) between the two groups.
In patients developing pneumothorax, those requiring a chest drain $(6 / 25,24 \%)$ showed no significant difference in FEV1 or FVC ( $p=0.76$ and $p=0.41$ respectively) to those managed conservatively. TLCO however was significantly lower in patients requiring chest drain insertion $(79 \% \pm 16.1 \%$ vs. $52.8 \% \pm$ $12.8 \%, \mathrm{p}=0.002)$.

Conclusion From our patient group, spirometry data and TLCO showed no correlation with the frequency of pneumothorax. In those patients developing pneumothorax, a low TLCO may predict the need for invasive management.

\section{P291 RELATIONSHIP OF IN VITRO PARTICLE SIZE TO IN VIVO LUNG DEPOSITION AND EXHALED FRACTION}

${ }^{1} \mathrm{G}$ Poli, ${ }^{2} \mathrm{~B}$ Lipworth. ${ }^{1}$ Chiesi Farmaceutici S.p.A., Parma, Italy; ${ }^{2}$ Scottish Centre for Respiratory Research, Ninewells Hospital, Dundee, UK

\subsection{6/thoraxjnl-2015-207770.427}

Introduction and objectives The particle size distribution and the median mass aerodynamic diameter (MMAD) of an inhaled product are important characteristics which may influence the deposition of the drug in the lung and as a consequence may also affect its therapeutic index. We evaluated the relationship between in vitro MMAD and in vivo lung deposition (LD, expressed as fraction of the delivered dose) and the exhaled fraction (EF), using relevant literature from scintigraphic studies conducted in healthy volunteers and asthmatic patients. Moreover the relationship between the ratio of EF to LD and MMAD has been further assessed.

Methods Data from 21 studies in healthy volunteers (15 with pressurised metered dose inhalers (pMDI) and 6 with dry powder inhalers (DPI)) and 11 studies in asthmatic patients (8 pMDI and 3 DPI) have been evaluated. Asthmatic patients had a FEV1 $>70 \%$ predicted, supporting pooling of the data with that of healthy volunteers. 

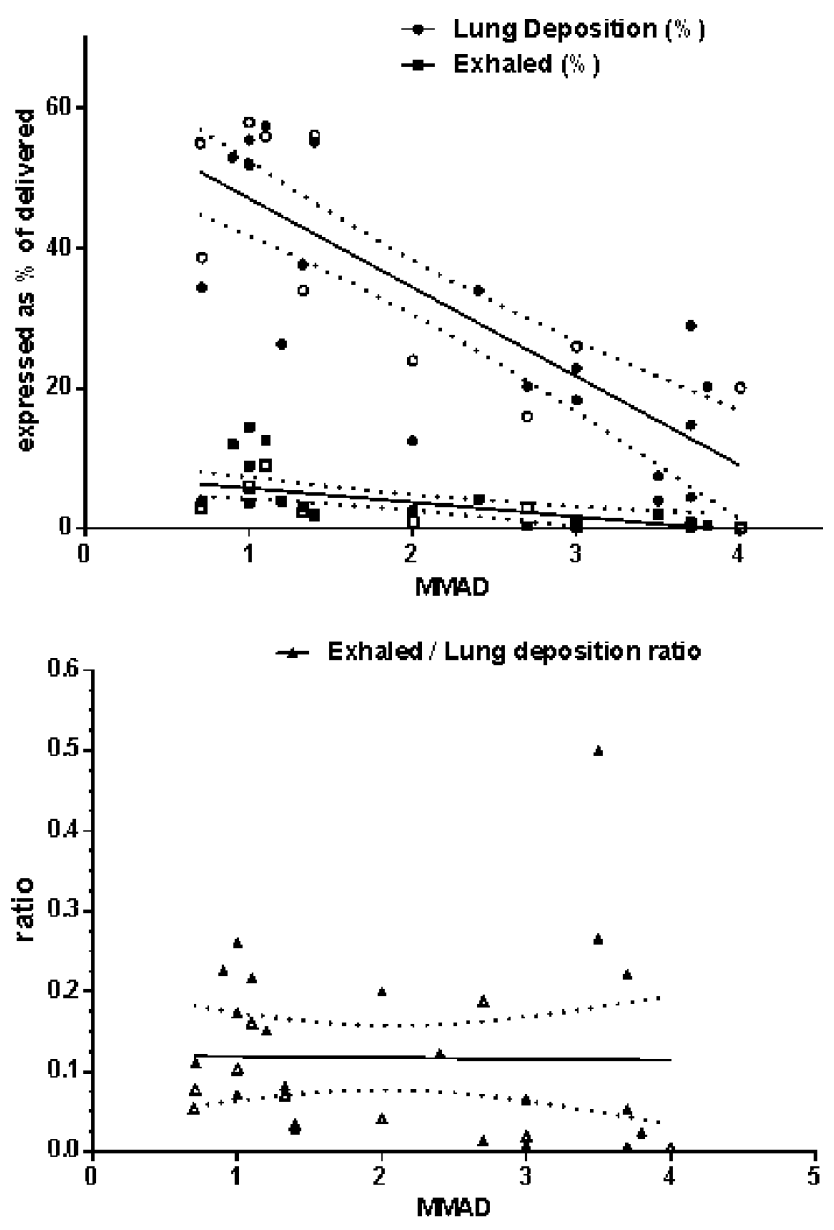

Full square, circle and triangle: healthy volunteers open square, circles and triangles: asth matic patients

Abstract P291 Figure 1 Lung deposition, exhaled fraction and ratio of exhaled vs lung deposition as a function of MMAD (regression line and the $95 \% \mathrm{Cl}$ )

Results LD increased when MMAD decreased, so that when MMAD is about $1 \mu \mathrm{m}$ the LD is more than $50 \%$ of the delivered dose and becomes markedly lower when MMAD approach 4 $\mu \mathrm{m}$. EF is low and did not change markedly. On the contrary, the ratio $\mathrm{EF} / \mathrm{LD}$ is independent of the MMAD, suggesting that the EF is proportional to the LD and not affected by MMAD. Conclusion These data demonstrate that the EF/LD ratio is independent from the MMAD providing reassurance that a smaller particle size will not be associated with a higher exhaled fraction.
Difficult symptom control and breathlessness

\begin{tabular}{l|l}
\hline M1 AN AUDIT OF ELECTRONIC OXYGEN PRESCRIBING AND \\
OXYGEN SATURATION READINGS SHOWING A HIGH \\
PREVALENCE OF RISK FACTORS FOR HYPERCAPNIA \\
AND A HIGH INCIDENCE OF IATROGENIC \\
HYPEROXAEMIA
\end{tabular}

P Whittemore, BR O'Driscoll. Salford Royal Foundation NHS Trust, Salford, UK

\subsection{6/thoraxjnl-2015-207770.428}

Background BTS audits have shown that about 14\% of UK hospital patients are on oxygen therapy at any given time but only half of these patients have a prescription or written order for oxygen use. Our 600 bed teaching hospital has electronic prescribing linked to an electronic bedside observations system (modified NEWS score). Hospital policy is to set a target oxygen saturation range for all in-patients. Patients score points if their oxygen saturation $\left(\mathrm{SpO}_{2}\right)$ falls below their target range or if $\mathrm{SpO}_{2}$ rises above their target range on oxygen therapy.

Methods We audited oxygen prescribing and $\mathrm{SpO}_{2}$ for all patients treated on medical and surgical wards during the month of December 2014. All data was contained within the electronic patient record.

Results We audited 80,391 sets of observations for 6,800 patients (2239 medical, 4561 surgical).

- $99.8 \%$ of all patients had an oxygen target range prescribed electronically

- $12.7 \%$ of all patients (18.9\% of medical patients and $9.6 \%$ of surgical patients) had risk factors for hypercapnia with a prescribed target range of $88-92 \%$ or less

- Overall $90.6 \%$ of oxygen saturation measurements were within target range (or above the target range breathing air). $59.9 \%$ of measurements on oxygen and $97.2 \%$ of observations on air were within the target range

- $3.7 \%$ of oximetry measurements were below the target range (7.9\% of those on oxygen)

- $5.8 \%$ of all oximetry measurements were above the target range due to use of oxygen $(32.2 \%$ of measurements on oxygen were above target range)

- For patients using oxygen therapy with target range 94-98\% or $88-92 \%$, the percent of measurements within range, below range or above range is shown in the Table 1

- $53.2 \%$ of observations on patients using oxygen with target range $88-92 \%$ showed $\mathrm{SpO}_{2}$ above target range

Conclusions An oxygen target range is prescribed for almost all inpatients at this hospital but hyperoxaemia (with associated risk of hypercapnia) remains prevalent amongst patients on oxygen therapy, especially those who have been identified as at increased risk of hypercapnia. This has led to a revised educational programme for nursing staff with an emphasis on keeping patients within their target range.

\section{M2 USING A TRANSPORTABLE OXYGEN CONCENTRATOR (TPOC) TO FACILITATE PROMPT AND SAFE HOSPITAL DISCHARGE}

${ }^{1} \mathrm{~F}$ Hamilton, ${ }^{2} \mathrm{G}$ Luxford, ${ }^{2} \mathrm{~J}$ Bott. ${ }^{1}$ Dolby Vivisol, Gatwick, UK; ${ }^{2} \mathrm{KSS}$ AHSN, South East England, UK

10.1136/thoraxjnl-2015-207770.429 